\title{
IMMUNOTHERAPY AND PATIENTS TREATED FOR CANCER WITH MICROSATELLITE INSTABILITY
}

\section{Authors:}

Raphaël Colle ${ }^{1} *$ Romain Cohen ${ }^{1,2}$, Delphine Cochereau ${ }^{1}$, Alex Duval $^{2}$, Olivier Lascols ${ }^{3}$, Daniel Lopez-Trabada $^{1}$, Pauline Afchain ${ }^{1}$, Isabelle Trouilloud ${ }^{1}$, Yann Parc ${ }^{2,}{ }^{4}$, Jérémie Lefevre ${ }^{2,}{ }^{4}$, JeanFrançois Fléjou ${ }^{2,5}$, Magali Svrcek ${ }^{2,5}$, Thierry André ${ }^{1,2}$

*: equal contribution

\section{Affiliation:}

1. Department of medical oncology, hôpital Saint-Antoine, AP-HP, 184 rue du Faubourg SaintAntoine, Paris 75012, France

2. Department of molecular biology, hôpital Saint-Antoine, APHP, 184 rue du Faubourg SaintAntoine, Paris 75012, France

3. INSERM, Unité Mixte de Recherche Scientifique 938, Centre de Recherche Saint-Antoine, Equipe Instabilité des Microsatellites et Cancer, Equipe labellisée par la Ligue Nationale contre le Cancer, 184 rue du Faubourg Saint-Antoine, Paris 75012, France

4. Department of digestive surgery, hôpital Saint-Antoine, APHP, 184 rue du Faubourg Saint-Antoine, Paris 75012, France

5. Department of Pathology, hôpital Saint-Antoine, APHP, 184 rue du Faubourg Saint-Antoine, Paris 75012, France

Keywords: mismatch repair deficiency, Lynch syndrom, immune checkpoint, pembrolizumab, nivolumab, endometrial cancer, colorectal cancer

Correspondance: Thierry André; Phone: +33 (0)1 719703 87; email: thierry.andre@aphp.fr 


\begin{abstract}
:
Microsatellite instability (MSI) is a genetic tumor phenotype linked to sporadic or inherited (Lynch syndrome) inactivating alterations of DNA mismatch repair genes. A broad spectrum of neoplasms exhibits MSI phenotype, mainly endometrial carcinoma, colorectal cancer and gastric adenocarcinoma. MSI tumors are characterized by dense immune infiltration and high load of tumor neo-antigens. Growing evidence is accumulating on the efficacy of immune checkpoint inhibition for patients treated for MSI solid tumors. We present a comprehensive overview of MSI phenotype, its biological landscape and current diagnostic methods. Then we will focus on MSI as a predictive biomarker of response to immune checkpoint inhibition in the context of colorectal cancer and noncolorectal tumors.
\end{abstract}

\title{
Résumé :
}

L'instabilité des microsatellites (MSI) est un phénotype génétique tumoral lié à l'inactivation sporadique ou héréditaire (syndrome de Lynch) des gènes de réparation des mésappariements de l'ADN. Un large spectre de localisations tumorales présente un phénotype MSI, principalement les cancers de l'endomètre, le cancer colorectal et les adénocarcinomes de l'estomac. Les tumeurs MSI sont caractérisées par un infiltrat inflammatoire important et une charge importante en néo-antigènes tumoraux. Les stratégies thérapeutiques ciblant les points de contrôle immunitaires semblent spécifiquement efficaces pour ces patients. Cette revue de la littérature présente les conséquences physiopathologiques et les méthodes diagnostiques du phénotype tumoral MSI, pour s'intéresser ensuite à l'épidémiologie des tumeurs MSI et les données actualisées concernant l'immunothérapie chez les patients présentant des tumeurs MSI, dans le cadre du cancer colorectal et des autres tumeurs solides associées

$\mathrm{au}$ phénotype

MSI. 


\section{INTRODUCTION}

The human tumor phenotype referred to as MSI (Microsatellite Instability) is associated with inactivating alterations in MMR genes (Mismatch Repair) [1-3]. MSI was first observed in inherited tumors associated with Lynch syndrome (LS) and later in sporadic colon, gastric and endometrial cancers [4]. The MSI and MSS (Microsatellite Stable) tumor subtypes are mutually exclusive and represent $15 \%$ and $85 \%$ of colorectal cancers (CRC), respectively. MSI tumors develop through a distinctive molecular pathway characterized by genetic instability in numerous microsatellite DNA repeat sequences throughout the genome (for review, see $[5,6]$ ).

MMR deficiency is not a direct transforming event. Most oncogenic alterations found in MMRdeficient (dMMR) tumors are somatic mutation events that occur as a result of MSI [7-9]. The MSI process is expected to be oncogenic when it affects DNA repeat sequences that have a functional role. Over the past 20 years, studies have reported several loss-of-function truncating mutations in coding repeats. Mutations in some of these coding repetitive sequences undergo positive selection during tumor development due to the growth advantage they confer to tumor cells. Importantly, the MSIdriven pathway to cancer also leads to the synthesis of aberrant and potentially immunogenic neoantigens by the tumor cells. A likely consequence is that MSI tumors are highly infiltrated with cytotoxic T-cell lymphocytes (CTLs) expressing activation markers, as well as Tc1 and Th1 phenotypes [10]. More generally, elevated expression levels for CTL/Th1/cytotoxicity markers are thought to constitute strong and independent predictors of relapse and overall survival in CRC patients regardless of their molecular phenotype, with a high density of lymphocyte infiltration consistently shown to be a strong indicator for prolonged survival [11].

Two signals are required to initiate an adaptive immune response by $\mathrm{T}$ cells; MHC-antigen peptide recognition by the $\mathrm{T}$ cell receptor (TCR) and co-stimulation via an array of receptors interacting with cognate ligands on antigen-presenting cells (APCs). Signaling via inhibitory receptors is necessary to regulate co-stimulatory receptor activity to ensure a measured response. However, during cancer progression, tumor-infiltrating $\mathrm{T}$ cells have been shown to display increased, chronic expression of 
different negative immune checkpoints (CK) like PD-1, LAG-3, and TIM-3, which cause T cells functional exhaustion and unresponsiveness [12]. These exhausted CD8 T cells fail to proliferate in response to antigen and lack critical anticancer effector functions such as cytotoxicity and IFN gamma cytokine secretion [13]. Such data gives the rational to develop antibodies that target these regulatory molecules. They are called checkpoint inhibitors (CKI) and could boost anticancer immune response. Importantly, the development of monoclonal antibodies (mAb) targeting CKI is going to revolution cancer therapy. Recent clinical trials demonstrated that mAb targeting PD-1/ PD-L1 could induce a major response in many types of cancers [14]. However, the clinical benefit in most tumor types was only observed in about $20 \%$ of patients, thus leading to the development of comprehensive studies, which could explain differences between responders and non-responders and help us generate predictive biomarkers for response to these therapies. Some reports suggest a better efficacy in tumors expressing PD-L1 and infiltrated by myeloid cells. Although PD-L1 is a predictive marker of efficacy for anti PD-1/PD-L1 therapies, it is not an ideal marker because of poor sensitivity and specificity. Rivzi et al. made the important observation that, in lung cancer, tumors with high rates of mutation and high rates of neo-antigens share better sensitivity to PD-1 mAb [15].

Recently, it was shown that MSI tumors were likely to persist in their hostile immune microenvironment because of immuno-escape and dramatic co-overexpression of CK-related proteins [16]. Based on these findings, in 2015, Le et al. evaluated the clinical activity of an anti-PD-1 CKI (pembrolizumab) in a cohort of metastatic carcinoma patients with or without MSI [17]. The results of this phase 2 study, together with results from another phase 2 study evaluating nivolumab (anti-PD-1 $\mathrm{mAb}$ ) with or without ipilimumab (anti-CTLA-4 mAb) [18], convincingly showed that MSI status was able to predict clinical benefit from CK blockade therapy. Thus, only tumors displaying MSI are likely to respond to PD-1 blockade, suggesting that MSI neoplasms are probably a useful model to study immune determinants associated with good response to anti-PD-1/PD-L1 mAb, or more generally to CK blockade therapy. 
Immunotherapy and MSI carcinomas - Determination of microsatellite instability and mismatch repair deficiency

\section{DETERMINATION OF MICROSATELLITE INSTABILITY AND MISMATCH REPAIR DEFICIENCY}

Revised guidelines for the clinical management of LS by a group of European experts recommend that testing all $\mathrm{CRC}$ (or individuals with $\mathrm{CRC}<70$ years) by immunohistochemistry (to identify dMMR tumors) or polymerase chain reaction (PCR; to identify MSI tumors) is useful for the identification of patients with LS (category of evidence IIb). The Mallorca group recommends the investigation of all CRC (or individuals with CRC $<70$ years) by immunohistochemistry of the four MMR proteins or PCR (grade of recommendation C). These tests should be accompanied by methods that identify MLH1 promoter methylation. Investigation of all endometrial cancers in individuals less than 70 years of age by immunohistochemistry or PCR can also be considered to improve identification (grade of recommendation C) [19]. In 2015, The European Society for medical Oncology (ESMO) recommended that every CRC patient should be tested for MSI and/or DNA MMR deficiency at the time of diagnosis as a first screen for LS [20]. The recent success of immunotherapy with PD-1 inhibition in dMMR CRC is likely to necessitate evaluation of MMR in all metastatic CRCs in the near future [17].

In tumor samples, the MSI phenotype can be determined by PCR according to international criteria [21]. It is correlated with the loss of MMR protein expression affecting MLH1, MSH2, MSH6, or PMS2 studied by immunohistochemistry [22].

\subsection{Polymerase chain reaction}

Microsatellites are highly repetitive DNA sequences of one to six nucleotides distributed throughout the genome, which are frequently copied incorrectly. The MMR system is responsible for the detection and the correction of these microsatellite-copying errors. Genotyping microsatellites using PCR is a standard method to detect MSI.

Held by the National Cancer Institute (NCI), Bethesda guidelines initially recommended the use of a standard panel of 5 microsatellites composed of 2 mononucleotidic repeats (BAT-25 and BAT-26) and 3 dinucleotidic repeats (D2S123, D5S346 et D17S250) [21]. When comparing marker length between normal and tumor tissue, MSI phenotype is defined by the instability of at least 2 microsatellites. In 
Immunotherapy and MSI carcinomas - Determination of microsatellite instability and mismatch repair deficiency

2002 , our group proposed a panel of 5 mononucleotidic repeats that obviated the necessity to analyze simultaneously non-tumor DNA [7], panel that was approved by the NCI for the screening of MSI tumors [23], with better specificity and sensitivity than the NCI panel [8]. With this method, 2 unstable markers are sufficient to classify tumors as MSI [24]. Main pitfalls encountered in detecting MSI tumor phenotype by PCR are the contamination of DNA tumor samples by DNA from normal tissue and low levels of tumor cells, notably in the context of mucinous tumors.

Our group recently reported a high frequency of mutations for the T17 mononucleotide repeat of the chaperone HSP110 (HT17) in MSI CRC [25]. Deletion of the HT17 repeat in tumor DNA leads to increased synthesis of a variant HSP110 isoform due to exon 9 skipping (HSP110DE9) $[25,26]$. We compared HT17 status with the pentaplex panel in a multicenter large cohort of patients: HT17 showed better sensitivity compared with the pentaplex panel [0.984 (95\% CI 0.968 to 0.995 ) versus 0.951 (95\% CI 0.925 to 0.972$)]$ and similar specificity [0.997 (95\% CI 0.989 to 1.000 ) for both) for the detection of MSI. Thus, HT17 DNA repeat seems to constitute a superior marker for the diagnosis of MSI phenotype in patients with CRC compared with the standard pentaplex panel [9].

\subsection{Immunohistochemistry}

Immunohistochemistry allows to study the expression of MMR proteins on histological section,. Physiologically, these proteins are ubiquitous and are located in the nucleus. They are particularly expressed in cells of the lower third of the crypts of mucosae, in stromal elements such as inflammatory cells and/or endothelial cells. Immunohistochemical testing consists in looking for the loss of expression of the studied protein by tumor cells, the two copies of the gene being inactivated in MSI tumors. The presence of nuclear staining in tumor cells, even when it is focal and weak, is good evidence of intact MMR protein. Each protein is considered lost if there is a complete loss of nuclear staining in tumor cells. An internal positive control (intact nuclear staining of stromal elements such as inflammatory cells and/or endothelial cells) is required for adequate evaluation. Cases showing a complete absence of nuclear staining pattern in both tumor cells and stromal elements are deemed uninterpretable. In this case, repeating the stain in search for positive non-neoplastic stromal or inflammatory cells should be done [27]. In some cases, the staining of internal controls can be stronger 
Immunotherapy and MSI carcinomas - Determination of microsatellite instability and mismatch repair deficiency

than the positive tumor cells; this staining has to be followed by molecular MSI analysis to confirm the presence of a defective DNA MMR system [28].

In their functional state, MMR proteins form heterodimers: MLH1 builds a functional complex with PMS2 (MutSalpha) and MSH2 dimerizes with MSH6, forming MutLalpha [29,30]. MLH1 and MSH2 proteins are the obligatory partners of their respective heterodimers. Mutations in the $M L H 1$ or $M S H 2$ gene result in proteolytic degradation of the respective dimer and consequent loss of both the obligatory and the secondary partner proteins. Loss of MLH1 and MSH2 proteins is exclusive, e.g. it concerns only one of the two proteins. In case of loss of MLH1 protein expression, a concurrent loss of PMS2 protein expression is also observed. In the same way, the extinction of MSH2 protein leads to concurrent extinction of MSH6. On the contrary, a mutation in one of the secondary genes, i.e. PMS2 or MSH6, does not usually lead to concurrent loss of the obligatory proteins (MLH1 or MSH2, respectively), probably due to interactions with other components of the MMR system such as MSH3, MLH3, and PMS1. The extinction of MSH2, MSH6 and PMS2, although not absolute, is a good argument in favor of a germline mutation of the gene. Loss of MLH1 protein expression can be related to either a germline mutation of $M L H 1$, or a methylation of its promoter (in sporadic cases). It is worth noting that a constitutional $3^{\prime}$ end deletion of EPCAM, which is immediately upstream of the $M S H 2$ gene, may cause LS through epigenetic silencing of $M S H 2$, thus leading to a loss of MSH2 protein expression [31].

Immunohistochemistry is an inexpensive and low time-consuming technique. It is routinely used in departments of pathology. It is an extremely sensitive technique, useable even for a small tumor sample (biopsy, mucinous adenocarcinoma which can be responsible of false negatives with molecular methods, rectal cancer nearly sterilized by neo-adjuvant radiotherapy). Moreover, in contrast to MSI testing, immunohistochemistry can help identify the affected gene, therefore directing germline mutation analysis to one gene, saving unnecessary analysis of other MMR genes [22].

Earlier studies focusing on MLH1 and MSH2 suggested that immunohistochemistry had lower sensitivity (85\%) than MSI testing (93\%) in predicting germline mutation [27]. When the four MMR proteins are tested, the correlation between the loss of MMR protein expression and MSI testing is excellent. In three main series including 1 144, 1066 and 1119 patients suffering from CRC, 
Immunotherapy and MSI carcinomas - Determination of microsatellite instability and mismatch repair deficiency

sensitivities for detection of MSI tumors by immunohistochemistry were $92 \%, 93 \%$ and $94 \%$ respectively [22,32,33]. In this setting, immunohistochemical analysis could replace microsatellite analysis of tumor DNA as the practical first-line screening test.

Immunohistochemistry is reliable in screening for mutations that result in truncation or degradation of the protein. However, false positives are possible in case of missense mutations, which result in mutant proteins that are catalytically inactive, but antigenically intact [34]. Moreover, a reduction of the intensity of staining for MSH6 has been described in rectal cancers after neoadjuvant chemoradiation [35]. In these cases, pre-treatment endoscopic biopsies, rather than operative material, may be used as the primary material for immunohistochemistry.

The heterogeneity of practices of fixation of tissue samples decreases the sensibility of the technique. In our experience, best results are obtained with samples fixed in $10 \%$ formalin. We should bear in mind that immunohistochemical techniques are not standardized enough and not perfectly reproducible. Thus, immunohistochemistry should only be performed in a specialized setting by experienced pathologists and staining results have to be evaluated with feedback of the molecular background of the tumor [28].

\subsection{Next-generation sequencing}

Next-generation sequencing (NGS) is becoming a widespread tool in profiling tumor genomic. NGS has been proposed as a diagnostic method to detect MSI tumors, hypothesizing that the mutational load of a multigene panel may accurately exclude pMMR cancers. Stadler et al. reported the analysis of 224 patients whose CRC had been profiled using a custom NGS assay [36]. Among these patients, 28 (13\%) harbored dMMR tumors and 196 (87\%) pMMR CRC. All tumors with less than 20 mutations $(\mathrm{N}=193)$ were pMMR. Of $31 \mathrm{CRC}$ with 20 mutations or more, $28(90 \%)$ were dMMR; the 3 remaining CRC harbored POLE mutation and exhibited a hypermutator phenotype with more than 150 mutations (median number of mutations among dMMR tumors: 50). However, NGS remains restricted to highly specialized laboratories and requires high-quality samples from both tumor and normal tissues. Secondly, Stadler et al used a custom multigene panel, consisting of deep sequencing of all exons and selected introns of 341 cancer-associated genes; consensus about NGS gene panel has 
Immunotherapy and MSI carcinomas - Determination of microsatellite instability and mismatch repair deficiency

to be found, as well as specific mutational load cut-off. NGS may be in the near future an attractive method to discriminate pMMR versus dMMR and POLE-mutated tumors. 


\section{MSI COLORECTAL CANCER}

\subsection{Epidemiology}

MSI CRC are associated with specific clinico-pathological characteristics: proximal colon, poor differentiation, mucinous component, high level of inflammatory infiltrate. They represent $15 \%$ to $20 \%$ of stage II and III CRC and are associated with better prognosis than pMMR tumors [37-41]. Fluoropyrimidine-based chemotherapy is not indicated in the adjuvant setting for patients with stage II dMMR CRC, given their favorable survival and the lack of impact of chemotherapy in this situation. Oxaliplatin-based chemotherapy remains the standard of treatment for patients with stage III CRC, regardless of their MMR status [37,39,42-44].

Representing approximately $5 \%$ of metastatic CRC, dMMR CRC prevalence is inferior in advanced diseases (stage IV) than in stage II and III tumors. This lower frequency highlights the weakened capacity for CRC with MMR deficiency to develop metastasis. In metastatic stage, dMMR status is associated with poor prognosis. Among 3063 patients with stage IV CRC included in 4 randomized phase III trials, those with dMMR tumors $(\mathrm{N}=153,5 \%)$ harbored reduced progression-free and overall survivals than patients with pMMR tumors (hazard ratio $=1.33,95 \% \mathrm{CI} 1.12-1.54$; hazard ratio $=1.35,95 \%$ CI 1.13-1.61, respectively) [45].

DMMR CRC are strongly associated with BRAFV600E mutation: there are 35\% of BRAFV600Emutated tumors among dMMR mCRC, and 21\% of dMMR tumors among BRAFV600E-mutated mCRC [45]. Actually, dMMR and BRAFV600E-mutated CRC are clustered together in the CMS 1 (consensus molecular subtype), which is characterized by favorable disease-free survival but dramatic prognosic after relapse [46]. Taking into account the negative impact of BRAFV600E mutation helps to decipher the prognostic profile of dMMR mCRC. Thus, the observed unfavorable prognosis of patients with dMMR mCRC may be partially due to BRAFV600E mutation [45,47].

\subsection{Sporadic and inherited dMMR colorectal cancer}

Standard immunohistochemical and biomolecular analysis are useful to distinguish sporadic dMMR and LS-related tumors. DMMR CRC with MLH2/MSH6, or isolated MSH6 or PMS2 loss of 
expression, should be considered as LS-related tumors, regardless of BRAF mutational status, and patients should be addressed for an oncogenetic research. It is important to note that patients with constitutional mutation of a MMR gene may be diagnosed with a BRAFV600E-mutated tumor [48,49]. On the opposite, dMMR CRC with MLH1 loss of expression may be from sporadic or inherited origin. Therefore, analysis of $B R A F$ mutational status and $M L H 1$ promoter methylation should be performed for MLH1-negative CRC. Sporadic MLH1-negative tumors are BRAFV600E-mutated and/or harbore MLH1 promoter hypermethylation. LS MLH1-negative CRC are BRAF wild-type without hypermethylation of $M L H 1$ promoter. Thus, algorithms have been developed to distinguish patients with dMMR CRC who should be searched for a constitutional mutation of MMR genes and those who should not [figure 1] [50-56].

Figure 1: Algorithm for the identification of sporadic colorectal cancers and tumors associated with Lynch syndrome

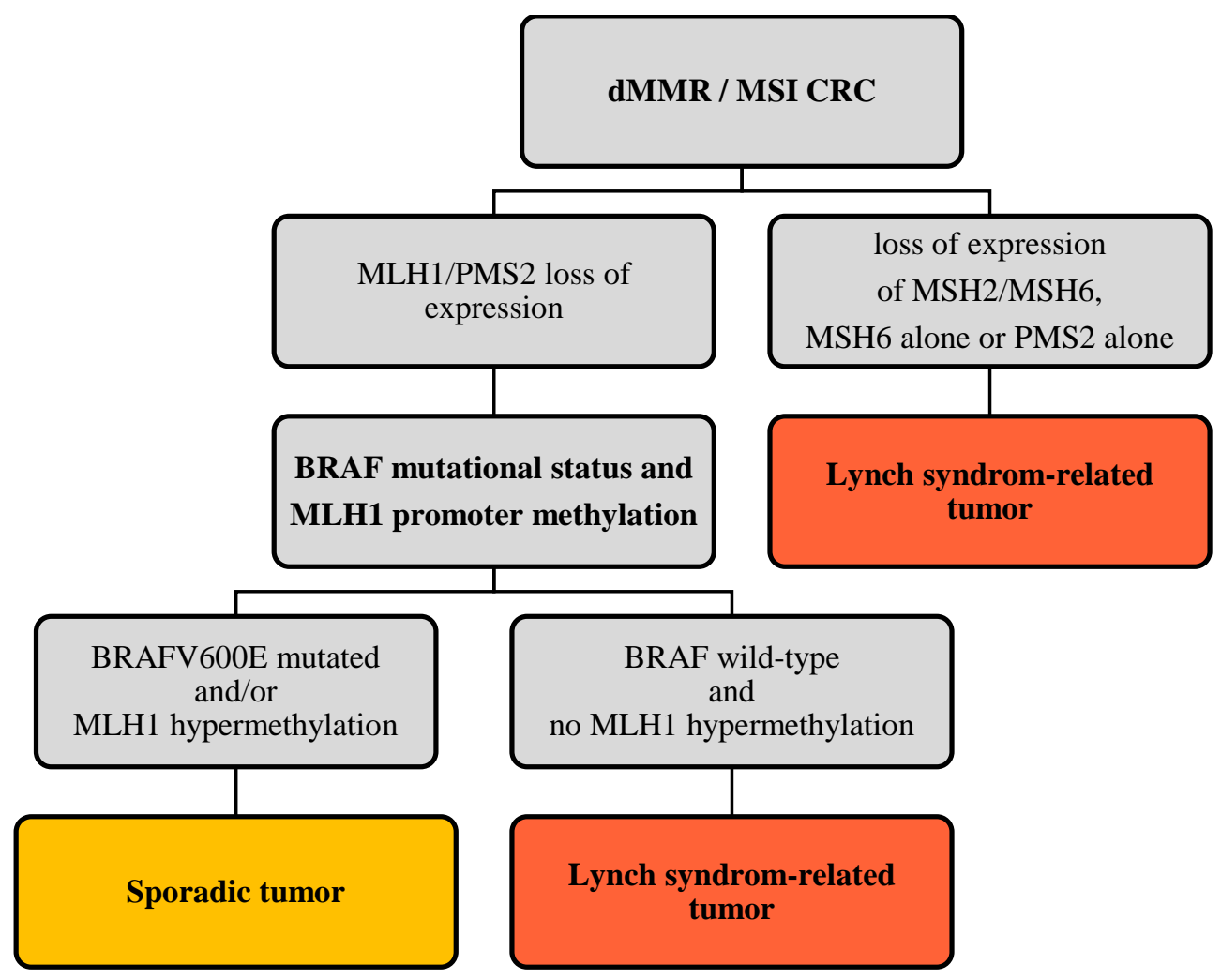




\subsection{Immunotherapy and dMMR colorectal cancer}

CK inhibition is a promising strategy for dMMR CRC. Proof-of-concept results published in the New England Journal of Medicine by Le et al. showed $40 \%$ of objective response with pembrolizumab for patients with dMMR CRC versus 0\% for those with pMMR tumors [17]. Updated analysis confirmed the high clinical activity of this anti-PD-1 mAb for dMMR mCRC. Objective response rate (ORR) was $50 \%$ for dMMR tumors $(\mathrm{N}=28)$ and $0 \%$ for pMMR CRC $(\mathrm{N}=25)$. Median progression-free survival (PFS) and overall survival (OS) were not reached in the dMMR cohort versus 2.4 months and 6 months in the pMMR cohort respectively $(\mathrm{HR}=0.135,95 \mathrm{CI} 0.043-0.191, \mathrm{P}<0.0001$ and $\mathrm{HR}=0.247$, IC95 0.117-0.589, P = 0.001, respectively) [table 1] [57]. Pembrolizumab is currently compared in a phase 3 randomized study with first-line standard-of-care chemotherapy in patients with dMMR mCRC with cross-over at progression (KEYNOTE-177; NCT02563002) [table 2].

Other CKI are currently evaluated for patients with dMMR mCRC. Notably, nivolumab, another antiPD-1 mAb, has been tested alone or in combination with ipilimumab, an anti-CTLA-4 mAb. Preliminary results presented at the ESMO 2016 Congress showed encouraging antitumor activity in patients with dMMR CRC $(\mathrm{N}=100)$ [18]. Seventy patients received nivolumab $3 \mathrm{mg} / \mathrm{kg}$ alone (N3) and 30 patients nivolumab $3 \mathrm{mg} / \mathrm{kg}$ plus ipilimumab $1 \mathrm{mg} / \mathrm{kg}(\mathrm{N} 3+\mathrm{I} 1)$ for 4 cycles $(\mathrm{Q} 3 \mathrm{~W})$ followed by nivolumab alone $3 \mathrm{mg} / \mathrm{kg}$ until disease progression or unacceptable toxicity (Q2W). ORR were $25.5 \%(\mathrm{~N} 3)$ and $33.3 \%(\mathrm{~N} 3+\mathrm{I} 1)$, with durable responses observed with both monotherapy and combination therapy. Only 1 partial response (5\%) was reported in the pMMR cohort $(\mathrm{N}=20)$. Median PFS among dMMR patients receiving N3 and N3 + I1 were 5.3 months and not yet reached. Median OS were 17.1 months and not yet reached, respectively. The safety profile of nivolumab with or without ipilimumab was acceptable with $14.3 \%(\mathrm{~N} 3)$ and $26.7 \%(\mathrm{~N} 3+\mathrm{I} 1)$ of grade 3-4 treatmentrelated adverse events and only 6 treatment discontinuations (16.1\%) related with drugs toxicities. Interestingly, clinical activity was observed regardless of BRAF mutational status (17\% of BRAFV600E-mutated tumors in the dMMR cohort), KRAS mutational status and PD-L1 expression levels. Only 1 partial response $(5 \%)$ was reported in the pMMR cohort $(\mathrm{N}=20)$. Even if no biomarker has yet been discovered among MSI tumors, MMR deficiency may be considered as a predictive 
biomarker for the efficacy of CKI. Thus, patients with metastatic dMMR CRC should be systematically identified because of the potential innovative therapeutic opportunities offered in the ongoing clinical trials [table 2].

Table 1: immune checkpoint inhibition in metastatic colorectal cancer

$\begin{array}{cccccccc}\text { Number of } & \text { CR } & \text { PR } & \text { SD } & \text { PD } & \text { NE } & \text { PFS } & \text { OS } \\ \text { patients } & (\%) & (\%) & (\%) & (\%) & (\%) & \text { (months) } & \text { (months) }\end{array}$

Pembrolizumab $10 \mathrm{mg} / \mathrm{kg}$

$\begin{array}{lcccccccc}\text { dMMR/MSI } & 28 & 11 & 46 & 32 & 4 & 7 & \text { NR } & \text { NR } \\ & & & & & & & & \\ \text { pMMR/MSS } & 25 & 0 & 0 & 4 & 11 & 40 & 2.3 & 5.98\end{array}$

Nivolumab $3 \mathrm{mg} / \mathrm{kg}$

$\begin{array}{lllllllll}\text { dMMR/MSI } & 47 & 0 & 26 & 30 & 36 & 9 & 5.3 & 17.1\end{array}$

Nivolumab $3 \mathrm{mg} / \mathrm{kg}+$ Ipilimumab $1 \mathrm{mg} / \mathrm{kg}$

$\begin{array}{lcccccccc}\text { dMMR/MSI } & 27 & 0 & 33 & 52 & 11 & 0 & \text { NR } & \text { NR } \\ \text { pMMR/MSS } & 10 & 0 & 0 & 20 & 70 & 10 & 1.3 & 3.7\end{array}$

CR: complete response; PR: partial response; SD: stable disease; PD: progression disease; NE: not evaluable; PFS: progression-free survival; OS: overall survival; NR: not reached; dMMR: deficient mismatch repair; pMMR: proficient mismatch repair; MSI: microsatellite instability; MSS: microsatellite stable 
Table 2: Ongoing trials evaluating immune checkpoint inhibition in MSI tumors

\begin{tabular}{|c|c|c|c|c|c|c|}
\hline Study identifier & Phase & Drug treatment & Drug mechanism & Tumor type & Current status & $\begin{array}{l}\text { French participating } \\
\text { center }\end{array}$ \\
\hline NCT02646748 & 1 & $\begin{array}{l}\text { Pembrolizumab } \\
\text { INCB039110 } \\
\text { INCB050465 }\end{array}$ & $\begin{array}{l}\text { anti-PD-1 mAb } \\
\text { JAK1 inhibitor } \\
\text { PI3K-delta inhibitor }\end{array}$ & $\begin{array}{l}\text { advanced and metastatic } \\
\text { dMMR / MSI cancers }\end{array}$ & recruiting & yes \\
\hline NCT02628067 & 2 & Pembrolizumab & anti-PD-1 mAb & $\begin{array}{l}\text { advanced and metastatic MSI } \\
\text { non-colorectal tumors }\end{array}$ & recruiting & yes \\
\hline NCT01876511 & 2 & Pembrolizumab & anti-PD-1 mAb & $\begin{array}{l}\text { advanced and metastatic MSI } \\
\text { cancers }\end{array}$ & recruiting & no \\
\hline NCT02563002 & 3 & $\begin{array}{l}\text { Pembrolizumab } \\
\text { versus chemotherapy }\end{array}$ & anti-PD-1 mAb & $\begin{array}{l}\text { stage IV dMMR / MSI } \\
\text { colorectal cancers }\end{array}$ & recruiting & yes \\
\hline NCT02060188 & 2 & $\begin{array}{l}\text { Nivolumab } \\
\text { plus Ipilimumab }\end{array}$ & $\begin{array}{l}\text { anti-PD-1 mAb } \\
\text { anti-CTLA-4 mAb }\end{array}$ & $\begin{array}{l}\text { stage IV MSI colorectal } \\
\text { cancers }\end{array}$ & recruiting & yes \\
\hline NCT02912559 & 3 & $\begin{array}{l}\text { Atezolizumab plus FOLFOX } \\
\text { versus FOLFOX }\end{array}$ & anti-PD-L1 mAb & $\begin{array}{l}\text { stage III dMMR / MSI } \\
\text { colorectal cancers }\end{array}$ & not yet recruiting & no \\
\hline
\end{tabular}




\section{MSI NON-COLORECTAL CANCERS}

\subsection{Epidemiology}

Most of studies on MSI phenotype focusing on CRC and detection techniques used being heterogeneous, epidemiological data on MSI non-colorectal cancers are incomplete. Endometrial, gastric, hepatocellular, thyroid cancers, melanoma, and sebaceous tumors harbor a MSI-high phenotype in more than $10 \%$ of cases. Ovarian and cervical cancers, oesophageous adenocarcinomas, soft tissue sarcomas, head and neck squamous cell carcinomas, kidney cancers and Ewing's sarcoma harbor a MSI phenotype in between 2 and $10 \%$ of cases. Finally, less than $2 \%$ of cutaneous squamous cell or basocellular carcinomas, prostate and non-small-cell lung cancers, osteosarcomas, glioblastomas, pancreas, breast and urothelial cancers and germ cell tumors exhibit MSI. This phenotype is rare in non-Hodgkin lymphomas (2\%); however it is specifically associated with immunodeficiency-related lymphomas. [ [table 3] [4,58,59].

Approximatively 20 to $30 \%$ of endometrial carcinomas harbor MMR deficiency [60-62]. MSI endometrial tumors are associated with high grade, vascular emboli and lymphatic invasion. More frequent in endometrioid tumors (30-40\%), MSI phenotype is rarely observed in serous ovarian cancers $(2 \%)$ but mainly related to LS $[61,63]$.

In ovarian cancer, MMR deficiency is observed in around 10\% of tumors and occurs in all histologic subtypes of ovarian cancer, with endometroid and mucinous cancers being most frequently affected. No association between MSI phenotype and prognosis has been described [64-66]. In the context of LS, dMMR tumors are associated with endometriod low grade histotype and early stage disease [67].

Little is known about MSI stomach adenocarcinoma (8 to $22 \%$ of all gastric epithelial cancers). However several studies showed an association between MSI phenotype and lower stage, older age and intestinal histological subtype [68-70]. Thus, despite the fact that MSI phenotype is a promising biomarker of efficacy for immunotherapy in a broad spectrum of tumors, clinical and molecular characterization of those MSI tumors remains incomplete. 
Table 3: Frequency of MSI phenotype in solid and hematological neoplasms

Colorectal cancer

Localized $[42,71,72]$ 


\subsection{Immunotherapy and dMMR non-colorectal cancers}

The phase 2 trial evaluating pembrolizumab in dMMR tumors was designed with a specific cohort including non-colorectal dMMR metastatic tumors $(\mathrm{N}=30)$ : endometrial cancers $(\mathrm{N}=9)$, ampullary tumors $(\mathrm{N}=7)$, pancreatic tumors $(\mathrm{N}=4)$, small bowel carcinoma $(\mathrm{N}=4)$, gastric cancer $(\mathrm{N}=3)$ and others $(\mathrm{N}=3)$. Pembrolizumab demonstrated impressive clinical activity with an objective response rate of 53\%, of which 9 complete responses (30\%) and 7 partial responses (23\%) [table 4]. The 1-year progression-free survival rate was $57 \%$ and the 1 -year overall survival rate $81 \%$ [78]. Following these major response rates in MSI tumors, several trials have already started with immunotherapy treatment. Some of them chose MSI phenotype as main inclusion criteria [table 2] whatever the type of primitive tumor, other trials are currently recruiting patients with tumors harboring frequent MSI phenotype such as endometrial and gastric cancers.

Table 4: Clinical efficacy of pembrolizumab in MSI non-colorectal carcinomas

\begin{tabular}{lccccc}
\hline Primary location & $\begin{array}{c}\text { Number of } \\
\text { patients }\end{array}$ & CR & PR & SD & PD \\
& 8 & 2 & 4 & 2 & 1 \\
\hline Endometrial & 6 & 2 & - & 3 & - \\
Ampullary / biliary & 4 & 1 & 2 & 1 & 1 \\
Small bowel & 3 & 1 & 1 & - & - \\
Gastric & 3 & - & 2 & 1 & 1 \\
Pancreas & 1 & - & - & - & - \\
Sarcoma & 1 & 1 & - & -
\end{tabular}

CR: complete response; PR: partial response; SD: stable disease; PD: progression disease 


\subsection{Constitutive mismatch repair deficiency}

Individuals with bi-allelic germline mutation in MMR genes suffer from constitutive MMR deficiency (CMMRD), an inherited cancer predisposition distinct from LS. This rare syndrome (reported in less than 200 patients) is associated with early-onset tumors such as CRC, brain tumors, sarcomas, lymphomas and leukemia [79]. CMMRD is characterized by MMR deficiency, and eventually MSI phenotype in both tumor cells and immortalized lymphoblastoid cells. Presence of MSI phenotype and tolerance to methylation in lymphoblastoid cell lines define CMMRD patients, as well as the identification of bi-allelic, deleterious germline MMR defects [80].

Glioblastoma multiforme due to CMMRD exhibit the highest mutational load among human cancers [81]. Interestingly, 2 cases have been reported about siblings treated with nivolumab for recurrent CMMRD glioblastoma multiforme. Nivolumab demonstrated high clinical activity with profound and durable responses in both cases, whereas survival is usually inferior to 6 months after recurrence [82]. Thus, CKI may be a major breakthrough for the treatment of CMMRD-related tumors. 


\section{CONCLUSION}

MMR deficiency is a driver of carcinogenesis is a large spectrum of human cancers. From sporadic origin or inherited (mainly related to LS, rarely due to CMMRD), MMR deficiency is responsible for MSI phenotype and can be detected through immunohistochemistry, PCR or NGS. Immune CKI is highly active in MSI / dMMR CRC and non-colorectal cancers, whereas immunotherapy is ineffective for patients with MSS CRC. Thus, MSI phenotype and MMR deficiency may be considered as positive predictive biomarkers for CKI efficacy. Determination of MSI or MMR status may be mandatory for tumors with high prevalence of MSI phenotype but this frequency cut-off remains to be defined. Clinical trial enrollment should be systematically considered for patients treated for MSI / dMMR cancers. 


\section{Bibliography:}

[1] Aaltonen LA, Peltomäki P, Leach FS, Sistonen P, Pylkkänen L, Mecklin JP, et al. Clues to the pathogenesis of familial colorectal cancer. Science 1993;260:812-6.

[2] Fishel R, Lescoe MK, Rao MR, Copeland NG, Jenkins NA, Garber J, et al. The human mutator gene homolog MSH2 and its association with hereditary nonpolyposis colon cancer. Cell 1993;75:1027-38.

[3] Ionov Y, Peinado MA, Malkhosyan S, Shibata D, Perucho M. Ubiquitous somatic mutations in simple repeated sequences reveal a new mechanism for colonic carcinogenesis. Nature 1993;363:558-61.

[4] Hause RJ, Pritchard CC, Shendure J, Salipante SJ. Classification and characterization of microsatellite instability across 18 cancer types. Nat Med 2016. doi:10.1038/nm.4191 (advance online publication).

[5] Duval A, Hamelin R. Mutations at Coding Repeat Sequences in Mismatch Repair-deficient Human Cancers Toward a New Concept of Target Genes for Instability. Cancer Res 2002;62:2447-2454.

[6] Hamelin R, Chalastanis A, Colas C, El Bchiri J, Mercier D, Schreurs A-S, et al. Clinical and molecular consequences of microsatellite instability in human cancers. Bull Cancer (Paris) 2008;95:121-32.

[7] Suraweera N, Duval A, Reperant M, Vaury C, Furlan D, Leroy K, et al. Evaluation of tumor microsatellite instability using five quasimonomorphic mononucleotide repeats and pentaplex PCR. Gastroenterology 2002;123:1804-11.

[8] Buhard O, Cattaneo F, Wong YF, Yim SF, Friedman E, Flejou J-F, et al. Multipopulation Analysis of Polymorphisms in Five Mononucleotide Repeats Used to Determine the Microsatellite Instability Status of Human Tumors. J Clin Oncol 2006;24:241-51.

[9] Buhard O, Lagrange A, Guilloux A, Colas C, Chouchène M, Wanherdrick K, et al. HSP110 T17 simplifies and improves the microsatellite instability testing in patients with colorectal cancer. $\mathrm{J}$ Med Genet 2016;53:377-84.

[10] Lothe RA, Peltomäki P, Meling GI, Aaltonen LA, Nyström-Lahti M, Pylkkänen L, et al. Genomic instability in colorectal cancer: relationship to clinicopathological variables and family history. Cancer Res 1993;53:5849-52.

[11] Galon J, Costes A, Sanchez-Cabo F, Kirilovsky A, Mlecnik B, Lagorce-Pagès C, et al. Type, Density, and Location of Immune Cells Within Human Colorectal Tumors Predict Clinical Outcome. Science 2006;313:1960-4.

[12] Blackburn SD, Shin H, Haining WN, Zou T, Workman CJ, Polley A, et al. Coregulation of $\mathrm{CD} 8+\mathrm{T}$ cell exhaustion by multiple inhibitory receptors during chronic viral infection. Nat Immunol 2009;10:29-37.

[13] Ferris RL, Lu B, Kane LP. Too Much of a Good Thing? Tim-3 and TCR Signaling in T Cell Exhaustion. J Immunol 2014;193:1525-30.

[14] Topalian SL, Drake CG, Pardoll DM. Immune Checkpoint Blockade: A Common Denominator Approach to Cancer Therapy. Cancer Cell 2015;27:450-61.

[15] Rizvi NA, Hellmann MD, Snyder A, Kvistborg P, Makarov V, Havel JJ, et al. Cancer immunology. Mutational landscape determines sensitivity to PD-1 blockade in non-small cell lung cancer. Science 2015;348:124-8.

[16] Llosa NJ, Cruise M, Tam A, Wicks EC, Hechenbleikner EM, Taube JM, et al. The Vigorous Immune Microenvironment of Microsatellite Instable Colon Cancer Is Balanced by Multiple Counter-Inhibitory Checkpoints. Cancer Discov 2015;5:43-51.

[17] Le DT, Uram JN, Wang H, Bartlett BR, Kemberling H, Eyring AD, et al. PD-1 Blockade in Tumors with Mismatch-Repair Deficiency. N Engl J Med 2015;372:2509-20.

[18] Overman MJ, Kopetz S, Lonardi S, McDermott R, Leone F, Leach J, et al. Nivolumab \pm ipilimumab treatment (Tx) efficacy, safety, and biomarkers in patients (Pts) with metastatic colorectal cancer (mCRC) with and without high microsatellite instability (MSI-H): results from the CheckMate-142 study. Ann Oncol 2016;27:supplement 6 (abstract 479P). 
[19] Vasen HFA, Blanco I, Aktan-Collan K, Gopie JP, Alonso A, Aretz S, et al. Revised guidelines for the clinical management of Lynch syndrome (HNPCC): recommendations by a group of European experts. Gut 2013;62:812-23.

[20] Stoffel EM, Mangu PB, Gruber SB, Hamilton SR, Kalady MF, Lau MWY, et al. Hereditary Colorectal Cancer Syndromes: American Society of Clinical Oncology Clinical Practice Guideline Endorsement of the Familial Risk-Colorectal Cancer: European Society for Medical Oncology Clinical Practice Guidelines. J Clin Oncol 2015;33:209-17.

[21] Boland CR, Thibodeau SN, Hamilton SR, Sidransky D, Eshleman JR, Burt RW, et al. A National Cancer Institute Workshop on Microsatellite Instability for Cancer Detection and Familial Predisposition: Development of International Criteria for the Determination of Microsatellite Instability in Colorectal Cancer. Cancer Res 1998;58:5248-57.

[22] Hampel H, Frankel WL, Martin E, Arnold M, Khanduja K, Kuebler P, et al. Screening for the Lynch syndrome (hereditary nonpolyposis colorectal cancer). N Engl J Med 2005;352:18511860.

[23] Umar A, Boland CR, Terdiman JP, Syngal S, Chapelle A d. 1., Ruschoff J, et al. Revised Bethesda Guidelines for Hereditary Nonpolyposis Colorectal Cancer (Lynch Syndrome) and Microsatellite Instability. J Natl Cancer Inst 2004;96:261-8.

[24] Goel A, Nagasaka T, Hamelin R, Boland CR. An optimized pentaplex PCR for detecting DNA mismatch repair-deficient colorectal cancers. PloS One 2010;5:e9393.

[25] Dorard C, de Thonel A, Collura A, Marisa L, Svrcek M, Lagrange A, et al. Expression of a mutant HSP110 sensitizes colorectal cancer cells to chemotherapy and improves disease prognosis. Nat Med 2011;17:1283-9.

[26] Collura A, Lagrange A, Svrcek M, Marisa L, Buhard O, Guilloux A, et al. Patients With Colorectal Tumors With Microsatellite Instability and Large Deletions in HSP110 T17 Have Improved Response to 5-Fluorouracil-Based Chemotherapy. Gastroenterology 2014;146:401411.

[27] Shia J. Immunohistochemistry versus microsatellite instability testing for screening colorectal cancer patients at risk for hereditary nonpolyposis colorectal cancer syndrome. Part I. The utility of immunohistochemistry. J Mol Diagn JMD 2008;10:293-300.

[28] Overbeek LIH, Ligtenberg MJL, Willems RW, Hermens RPMG, Blokx WAM, Dubois SV, et al. Interpretation of immunohistochemistry for mismatch repair proteins is only reliable in a specialized setting. Am J Surg Pathol 2008;32:1246-51.

[29] Kadyrov FA, Dzantiev L, Constantin N, Modrich P. Endonucleolytic Function of MutL $\alpha$ in Human Mismatch Repair. Cell 2006;126:297-308.

[30] Acharya S, Wilson T, Gradia S, Kane MF, Guerrette S, Marsischky GT, et al. hMSH2 forms specific mispair-binding complexes with hMSH3 and hMSH6. Proc Natl Acad Sci 1996;93:13629-13634.

[31] Ligtenberg MJL, Kuiper RP, Chan TL, Goossens M, Hebeda KM, Voorendt M, et al. Heritable somatic methylation and inactivation of MSH2 in families with Lynch syndrome due to deletion of the 3' exons of TACSTD1. Nat Genet 2009;41:112-7.

[32] Lindor NM, Burgart LJ, Leontovich O, Goldberg RM, Cunningham JM, Sargent DJ, et al. Immunohistochemistry versus microsatellite instability testing in phenotyping colorectal tumors. J Clin Oncol Off J Am Soc Clin Oncol 2002;20:1043-8.

[33] Engel C, Forberg J, Holinski-Feder E, Pagenstecher C, Plaschke J, Kloor M, et al. Novel strategy for optimal sequential application of clinical criteria, immunohistochemistry and microsatellite analysis in the diagnosis of hereditary nonpolyposis colorectal cancer. Int J Cancer 2006;118:115-22.

[34] Peltomäki P, Vasen H. Mutations Associated with HNPCC Predisposition - Update of ICGHNPCC/INSiGHT Mutation Database. Dis Markers 2004;20:269-76.

[35] Bao F, Panarelli NC, Rennert H, Sherr DL, Yantiss RK. Neoadjuvant Therapy Induces Loss of MSH6 Expression in Colorectal Carcinoma: Am J Surg Pathol 2010;34:1798-804.

[36] Stadler ZK, Battaglin F, Middha S, Hechtman JF, Tran C, Cercek A, et al. Reliable Detection of Mismatch Repair Deficiency in Colorectal Cancers Using Mutational Load in Next-Generation Sequencing Panels. J Clin Oncol 2016;34:2141-7. 
[37] Ribic CM, Sargent DJ, Moore MJ, Thibodeau SN, French AJ, Goldberg RM, et al. Tumor microsatellite-instability status as a predictor of benefit from fluorouracil-based adjuvant chemotherapy for colon cancer. N Engl J Med 2003;349:247-257.

[38] Sargent DJ, Marsoni S, Monges G, Thibodeau SN, Labianca R, Hamilton SR, et al. Defective Mismatch Repair As a Predictive Marker for Lack of Efficacy of Fluorouracil-Based Adjuvant Therapy in Colon Cancer. J Clin Oncol 2010;28:3219-26.

[39] Sinicrope FA, Foster NR, Thibodeau SN, Marsoni S, Monges G, Labianca R, et al. DNA Mismatch Repair Status and Colon Cancer Recurrence and Survival in Clinical Trials of 5Fluorouracil-Based Adjuvant Therapy. J Natl Cancer Inst 2011;103:863-75.

[40] Hutchins G, Southward K, Handley K, Magill L, Beaumont C, Stahlschmidt J, et al. Value of Mismatch Repair, KRAS, and BRAF Mutations in Predicting Recurrence and Benefits From Chemotherapy in Colorectal Cancer. J Clin Oncol 2011;29:1261-70.

[41] Roth AD, Tejpar S, Delorenzi M, Yan P, Fiocca R, Klingbiel D, et al. Prognostic Role of KRAS and BRAF in Stage II and III Resected Colon Cancer: Results of the Translational Study on the PETACC-3, EORTC 40993, SAKK 60-00 Trial. J Clin Oncol 2010;28:466-74.

[42] André T, Gramont A de, Vernerey D, Chibaudel B, Bonnetain F, Tijeras-Raballand A, et al. Adjuvant Fluorouracil, Leucovorin, and Oxaliplatin in Stage II to III Colon Cancer: Updated 10Year Survival and Outcomes According to BRAF Mutation and Mismatch Repair Status of the MOSAIC Study. J Clin Oncol 2015;33:4176-87.

[43] Zaanan A, Cuilliere-Dartigues P, Guilloux A, Parc Y, Louvet C, Gramont A de, et al. Impact of p53 expression and microsatellite instability on stage III colon cancer disease-free survival in patients treated by 5 -fluorouracil and leucovorin with or without oxaliplatin. Ann Oncol 2010;21:772-80.

[44] Tougeron D, Mouillet G, Trouilloud I, Lecomte T, Coriat R, Aparicio T, et al. Efficacy of Adjuvant Chemotherapy in Colon Cancer With Microsatellite Instability: A Large Multicenter AGEO Study. J Natl Cancer Inst 2016;108:djv438.

[45] Venderbosch S, Nagtegaal ID, Maughan TS, Smith CG, Cheadle JP, Fisher D, et al. Mismatch Repair Status and BRAF Mutation Status in Metastatic Colorectal Cancer Patients: A Pooled Analysis of the CAIRO, CAIRO2, COIN, and FOCUS Studies. Clin Cancer Res 2014;20:532230.

[46] Guinney J, Dienstmann R, Wang X, de Reyniès A, Schlicker A, Soneson C, et al. The consensus molecular subtypes of colorectal cancer. Nat Med 2015;21:1350-6.

[47] Goldstein J, Tran B, Ensor J, Gibbs P, Wong HL, Wong SF, et al. Multicenter retrospective analysis of metastatic colorectal cancer (CRC) with high-level microsatellite instability (MSI-H). Ann Oncol 2014;25:1032-8.

[48] Robinson KL, Liu T, Vandrovcova J, Halvarsson B, Clendenning M, Frebourg T, et al. Lynch Syndrome (Hereditary Nonpolyposis Colorectal Cancer) Diagnostics. J Natl Cancer Inst 2007;99:291-9.

[49] Senter L, Clendenning M, Sotamaa K, Hampel H, Green J, Potter JD, et al. The Clinical Phenotype of Lynch Syndrome Due to Germ-Line PMS2 Mutations. Gastroenterology 2008;135:419-428.

[50] Loughrey MB, Waring PM, Tan A, Trivett M, Kovalenko S, Beshay V, et al. Incorporation of somatic BRAF mutation testing into an algorithm for the investigation of hereditary nonpolyposis colorectal cancer. Fam Cancer 2007;6:301-10.

[51] Capper D, Voigt A, Bozukova G, Ahadova A, Kickingereder P, von Deimling A, et al. BRAF V600E-specific immunohistochemistry for the exclusion of Lynch syndrome in MSI-H colorectal cancer: BRAF V600E Immunohistochemistry in MSI-H Colorectal Cancer. Int J Cancer 2013;133:1624-30.

[52] Nakagawa H, Nagasaka T, Cullings HM, Notohara K, Hoshijima N, Young J, et al. Efficient molecular screening of Lynch syndrome by specific 3' promoter methylation of the MLH1 or BRAF mutation in colorectal cancer with high-frequency microsatellite instability. Oncol Rep 2009;21:1577-83.

[53] Thiel A, Heinonen M, Kantonen J, Gylling A, Lahtinen L, Korhonen M, et al. BRAF mutation in sporadic colorectal cancer and Lynch syndrome. Virchows Arch 2013;463:613-21. 
[54] Bessa X, Ballesté B, Andreu M, Castells A, Bellosillo B, Balaguer F, et al. A Prospective, Multicenter, Population-Based Study of BRAF Mutational Analysis for Lynch Syndrome Screening. Clin Gastroenterol Hepatol 2008;6:206-14.

[55] Parsons MT, Buchanan DD, Thompson B, Young JP, Spurdle AB. Correlation of tumour BRAF mutations and MLH1 methylation with germline mismatch repair (MMR) gene mutation status: a literature review assessing utility of tumour features for MMR variant classification. J Med Genet 2012;49:151-7.

[56] Roth RM, Hampel H, Arnold CA, Yearsley MM, Marsh WL, Frankel WL. A Modified Lynch Syndrome Screening Algorithm in Colon Cancer: BRAF Immunohistochemistry Is Efficacious and Cost Beneficial. Am J Clin Pathol 2015;143:336-43.

[57] Le DT, Uram JN, Wang H, Bartlett BR, Kemberling H, Eyring AD, et al. Programmed death-1 blockade in mismatch repair deficient colorectal cancer. J Clin Oncol 2016;34:suppl; abstr 103

[58] Dudley JC, Lin M-T, Le DT, Eshleman JR. Microsatellite Instability as a Biomarker for PD-1 Blockade. Clin Cancer Res 2016;22:813-20.

[59] Duval A, Raphael M, Brennetot C, Poirel H, Buhard O, Aubry A, et al. The mutator pathway is a feature of immunodeficiency-related lymphomas. Proc Natl Acad Sci U S A 2004;101:50025007.

[60] Cancer Genome Atlas Research Network, Kandoth C, Schultz N, Cherniack AD, Akbani R, Liu Y, et al. Integrated genomic characterization of endometrial carcinoma. Nature 2013;497:67-73.

[61] Zighelboim I, Goodfellow PJ, Gao F, Gibb RK, Powell MA, Rader JS, et al. Microsatellite instability and epigenetic inactivation of MLH1 and outcome of patients with endometrial carcinomas of the endometrioid type. J Clin Oncol Off J Am Soc Clin Oncol 2007;25:2042-8.

[62] Stelloo E, Jansen AML, Osse EM, Nout RA, Creutzberg CL, Ruano D, et al. Practical guidance for mismatch repair-deficiency testing in endometrial cancer. Ann Oncol 2016:mdw542.

[63] Gargiulo P, Della Pepa C, Berardi S, Califano D, Scala S, Buonaguro L, et al. Tumor genotype and immune microenvironment in POLE-ultramutated and MSI-hypermutated Endometrial Cancers: New candidates for checkpoint blockade immunotherapy? Cancer Treat Rev 2016;48:61-8.

[64] V S, Bhagat R, C S P, V R P, Krishnamoorthy L. Microsatellite instability, promoter methylation and protein expression of the DNA mismatch repair genes in epithelial ovarian cancer. Genomics 2014;104:257-63.

[65] Arzimanoglou II, Lallas T, Osborne M, Barber H, Gilbert F. Microsatellite instability differences between familial and sporadic ovarian cancers. Carcinogenesis 1996;17:1799-804.

[66] Murphy MA, Wentzensen N. Frequency of mismatch repair deficiency in ovarian cancer: a systematic review This article is a US Government work and, as such, is in the public domain of the United States of America. Int J Cancer 2011;129:1914-22.

[67] Norquist BM, Harrell MI, Brady MF, Walsh T, Lee MK, Gulsuner S, et al. Inherited Mutations in Women With Ovarian Carcinoma. JAMA Oncol 2016;2:482-90.

[68] Toyota M, Ahuja N, Suzuki H, Itoh F, Ohe-Toyota M, Imai K, et al. Aberrant Methylation in Gastric Cancer Associated with the CpG Island Methylator Phenotype. Cancer Res 1999;59:5438-42.

[69] Bass AJ, Thorsson V, Shmulevich I, Reynolds SM, Miller M, Bernard B, et al. Comprehensive molecular characterization of gastric adenocarcinoma. Nature 2014;513:202-9.

[70] Seo HM, Chang YS, Joo SH, Kim YW, Park Y-K, Hong SW, et al. Clinicopathologic characteristics and outcomes of gastric cancers with the MSI-H phenotype. J Surg Oncol 2009;99:143-7.

[71] Gavin PG, Colangelo LH, Fumagalli D, Tanaka N, Remillard MY, Yothers G, et al. Mutation Profiling and Microsatellite Instability in Stage II and III Colon Cancer: An Assessment of Their Prognostic and Oxaliplatin Predictive Value. Clin Cancer Res 2012;18:6531-41.

[72] Taieb J, Zaanan A, Le Malicot K, Julié C, Blons H, Mineur L, et al. Prognostic Effect of BRAF and KRAS Mutations in Patients With Stage III Colon Cancer Treated With Leucovorin, Fluorouracil, and Oxaliplatin With or Without Cetuximab: A Post Hoc Analysis of the PETACC-8 Trial. JAMA Oncol 2016;2:643. 
[73] Tran B, Kopetz S, Tie J, Gibbs P, Jiang Z-Q, Lieu CH, et al. Impact of BRAF mutation and microsatellite instability on the pattern of metastatic spread and prognosis in metastatic colorectal cancer. Cancer 2011;117:4623-32.

[74] Nakata B, Wang YQ, Yashiro M, Nishioka N, Tanaka H, Ohira M, et al. Prognostic value of microsatellite instability in resectable pancreatic cancer. Clin Cancer Res Off J Am Assoc Cancer Res 2002;8:2536-40.

[75] Maple JT, Smyrk TC, Boardman LA, Johnson RA, Thibodeau SN, Chari ST, et al. Defective DNA mismatch repair in long-term ( $\geq 3$ years) survivors with pancreatic cancer. Pancreatology 2005;5:220-8.

[76] Farris AB, Demicco EG, Le LP, Finberg KE, Miller J, Mandal R, et al. Clinicopathologic and Molecular Profiles of Microsatellite Unstable Barrett Esophagus-associated Adenocarcinoma: Am J Surg Pathol 2011;35:647-55.

[77] Chiappini F, Gross-Goupil M, Saffroy R, Azoulay D, Emile J-F, Veillhan L-A, et al. Microsatellite instability mutator phenotype in hepatocellular carcinoma in non-alcoholic and non-virally infected normal livers. Carcinogenesis 2004;25:541-7.

[78] Diaz LA, Uram JN, Wang H, Bartlett B, Kemberling H, Eyring A, et al. Programmed death-1 blockade in mismatch repair deficient cancer independent of tumor histology. J Clin Oncol 2016;34:suppl; abstr 3003.

[79] Lavoine N, Colas C, Muleris M, Bodo S, Duval A, Entz-Werle N, et al. Constitutional mismatch repair deficiency syndrome: clinical description in a French cohort. J Med Genet 2015;52:770-8.

[80] Bodo S, Colas C, Buhard O, Collura A, Tinat J, Lavoine N, et al. Diagnosis of Constitutional Mismatch Repair-Deficiency Syndrome Based on Microsatellite Instability and Lymphocyte Tolerance to Methylating Agents. Gastroenterology 2015;149:1017-1029.e3.

[81] Shlien A, Campbell BB, de Borja R, Alexandrov LB, Merico D, Wedge D, et al. Combined hereditary and somatic mutations of replication error repair genes result in rapid onset of ultrahypermutated cancers. Nat Genet 2015;47:257-62.

[82] Bouffet E, Larouche V, Campbell BB, Merico D, Borja R de, Aronson M, et al. Immune Checkpoint Inhibition for Hypermutant Glioblastoma Multiforme Resulting From Germline Biallelic Mismatch Repair Deficiency. J Clin Oncol 2016;34:2206-2211 